\title{
Cost-Benefit Analysis of an Enhanced Recovery Program for Gastrectomy A Retrospective Controlled Analysis
}

\author{
Valentine Luzuy-Guarnero $^{1}$ (i) $\cdot$ Caroline Gronnier $^{2} \cdot$ Sergio Figuereido $^{1} \cdot$ Styliani Mantziari $^{1}$ • \\ Markus Schäfer $^{1} \cdot$ Nicolas Demartines ${ }^{1} \cdot$ Pierre Allemann $^{1}$
}

\begin{abstract}
Background Enhanced recovery programs (ERP) demonstrated decreased postoperative complication rate and reduced length of stay (LOS). Recently, data on the financial impact revealed cost reduction for colorectal, liver and pancreatic surgery. The present study aimed to assess the cost-effectiveness of ERP in gastric surgery.

Methods ERP based on enhanced recovery after surgery (ERAS $\left.{ }^{\circledR}\right)$ society guidelines was implemented in our institution, in June 2014. Consecutive patients undergoing gastric surgery after ERP implementation $(n=71)$ were compared to a control group of consecutive patients operated before ERP implementation $(n=58)$. Primary endpoint was cost-effectiveness including detailed perioperative costs. Secondary endpoints were postoperative complications and LOS. Standard statistical testing (means, Mann-Whitney Fisher's exact T test or Pearson Chi-square test) was used.

Results Both groups were comparable regarding demographic details. Mean (SD) overall costs per patient were lower in the ERP group $(€ 33,418(17,901)$ vs $€ 39,804(27,288), P=0.027)$. Lower costs were found for anesthesia and operating room ( $-€ 2356)$, intensive or intermediate care ( $€ 88629)$, medication $(-€ 1$ 196)), physiotherapy $(-€ 611)$, laboratory $(-€ 1625)$ ) and blood transfusion (-€977). Overall complication rates in ERP and control group (51\% vs $62 \%, P=0.176)$ were similar. Mean length of stay (SD) (14(13) days vs $17(11)$ days, $P=0.037$ ) was shorter in the ERP group.

Conclusion ERP significantly reduces overall, preoperative and postoperative costs in patients undergoing major gastric surgery.
\end{abstract}

\section{Introduction}

Since the 1990s, various and not always well-defined fast tracks or enhanced recovery protocols (ERP) were promoted worldwide. They consist in multimodal perioperative management programs, aiming to improve

Nicolas Demartines

demartines@chuv.ch

1 Department of Visceral Surgery, Centre Hospitalier Universitaire Vaudois (CHUV), Rue du Bugnon 46, CH-1011 Lausanne, Switzerland

2 Digestive Surgery, CHU of Bordeaux, Bordeaux, France postoperative recovery [1]. Evidence-based guidelines were implemented for colon and rectal surgery and for both pancreatic and liver surgery [2-8]. For these types of surgery, many studies demonstrated substantial benefits like reduced length of stay (LOS) and reduced complications rate [9-14].

Recently, the ERAS ${ }^{\circledR}$ Society published guidelines for gastrectomy [15]. Due to limited experience, data remain scarce. Two recent meta-analyses, including only preliminary data, showed promising results, mainly shorter LOS without increased complications [16, 17].

In addition, minimally invasive surgery (MIS) for gastrectomy is now validated and established and some studies 
suggested that combining ERP protocol with MIS could improve postoperative recovery and early postoperative nutritional status as well as reduce postoperative stress reaction [18-20].

Currently, reducing costs is increasingly a major issue for national healthcare systems. ERPs have demonstrated to reduce the costs for colorectal [21], pancreatic [22] and liver surgery [23]. The question remained open for gastric surgery. Kim et al. [24] showed no differences in hospital charges. However, costs were not the primary endpoint of the study and the number of patients was low. More recently, Liu et al. [20] showed significantly lower charges, but only medical costs were assessed.

The aim of the present study was to analyze the complete cost-effectiveness of ERP in gastric surgery. Secondary endpoints were to assess LOS and morbidity rate.

\section{Methods}

An ERP for gastric surgery based on the recommendations of the ERAS ${ }^{\circledR}$ Society [15] was implemented in our department in June 2014. The detail of the various pre-, intra- and postoperative elements included in the protocol is listed in Table 1 . The medical and nursing staff were already familiar with ERAS ${ }^{\circledR}$ protocols and pathways, since such protocols were previously implemented for colorectal, pancreatic and liver surgery in 2011, 2012 and 2013, respectively. Furthermore, the dedicated ERAS ${ }^{\circledR}$ team which included surgeons, anesthetists, nurses and nutritionists did already exist and was well trained. The study protocol was approved by the local Ethical Committee (CER-VD, protocol number: 2016-01,075). Moreover, all patients had signed the institutional general informed consent for clinical research.

\section{Patient selection}

A prospective ERP cohort of consecutive patients was compared with a retrospective control group (standard care). All consecutive patients with total or partial gastrectomy from June 2014 to December 2019 were included in the ERP group. The control group included all consecutive patients operated from January 2010 to May 2014 before ERP implementation. There was no selection based on the pathological condition (benign or malignant). However, patients with any kind of wedge gastric resection or gastrectomy as part of a multivisceral resection and patients with missing cost-related data were excluded.

According to the study of Staiger et al. [25], patients with a high overall postoperative morbidity index are prone to induce significant selection bias, particularly in costs analysis. For this reason, we decided to exclude patients with several Grade IIIb or IV complications leading to a Comprehensive Complication Index (CCI) [26] higher than 50 from the cost's analysis.

\section{Assessment of postoperative outcomes and discharge criteria}

Postoperative complications were graded according to the Clavien classification [27]. Grade IIIa-IVb were defined as major complications. Postoperative mortality (grade V) was defined as death during the first 30 days after the index operation or during the hospital stay [27]. The CCI was also calculated for each patient.

The LOS was calculated from the day of the operation to the day of discharge from hospital. Finally, compliance rate was calculated in the ERP group as the average of the compliance to each ERAS ${ }^{\circledR}$ items (Table 1), which correspond to the number of fulfilled ERAS ${ }^{\circledR}$ items divided by the total number of items.

\section{Cost analysis}

Detailed costs for each patient were extracted from the hospital accounting database via the administration service. Costs were calculated until the day the patient leaves the hospital. They were divided into intraoperative and preoperative/postoperative costs. Intraoperative costs included costs from anesthesia, operation room (OR) and disposable materials used in the OR. Anesthesia costs were calculated per minute based on the duration of anesthesia (including costs of anesthetists, nurse anesthetists, materials and drugs). OR costs were based on the OR occupation in minutes at our institutional standard rate. Preoperative and postoperative costs included: intensive care unit (ICU) and intermediate care unit (IC) costs, calculated per day, based on the Project Research in Nursing (PRN) score [28], medical care, nursing care, physiotherapy, medication, blood transfusion and testing, laboratory test, radiology, pathology, housing, administration and other (social work, priest and occupational therapy). Medical care included all clinical activities performed by doctors, including surgeon's costs and the costs of other non-operative procedures (endoscopy, drainage as example). Nursing care costs were measured per day outside intensive and intermediate care units, based on the PRN score. Costs of housing were counted per day, whereas administration costs were counted per patient admission.

\section{Cost-minimization analysis}

The cost-minimization analysis was performed from a healthcare provider's perspective to assess savings per patient in hospital. This analysis corresponded to the 
Table 1 Perioperative care used before and after the introduction of the ERP

\begin{tabular}{|c|c|c|}
\hline & ERP & Control group \\
\hline $\begin{array}{l}\text { Patient counseling } \\
\text { and education }\end{array}$ & Preadmission counseling and written information & No standardized information \\
\hline Fasting & Clear fluids until $2 \mathrm{~h}$, solids $6 \mathrm{~h}$ before surgery & $\begin{array}{l}\text { Solid and fluid fasting from } \\
\text { midnight }\end{array}$ \\
\hline Carbohydrate drinks & $800 \mathrm{ml}$ on evening and $400 \mathrm{ml} 2 \mathrm{~h}$ before surgery & None \\
\hline Premedication & No premedication & At discretion of the anethetist \\
\hline Thromboprophylaxis & LMW heparin $12 \mathrm{~h}$ before surgery, IPC & $\begin{array}{l}\text { LMW heparin } 12 \mathrm{~h} \text { before } \\
\text { surgery }\end{array}$ \\
\hline PONV prophylaxis & Droperidol + ondansetron \pm betamethasone & Not routinely used \\
\hline $\begin{array}{r}\text { Hypothermia } \\
\text { prevention }\end{array}$ & Active warming with air blanket & $\begin{array}{l}\text { Active warming with air } \\
\text { blanket }\end{array}$ \\
\hline $\begin{array}{l}\text { Antibiotic } \\
\text { prophylaxis }\end{array}$ & Cefuroxime $1.5 \mathrm{~g}$ at induction & Cefuroxime $1.5 \mathrm{~g}$ at induction \\
\hline $\begin{array}{l}\text { Balanced } \\
\quad \text { intraveinous fluids }\end{array}$ & $\begin{array}{l}\text { Near-zero fluid balance. Balanced crystalloids should be preferred to } 0,9 \% \text { saline. } \\
\text { Postoperative crystalloïds } 1000 \mathrm{ml} \text { during the first } 24 \mathrm{~h} \text {, then stop }\end{array}$ & No guidance \\
\hline $\begin{array}{l}\text { Postoperative } \\
\text { analgesia }\end{array}$ & $\begin{array}{l}\text { Epidural for laparotomy. Paracetamol, metamizole and oxycodone-naloxone (when } \\
\text { epidural is removed) }\end{array}$ & $\begin{array}{l}\text { No standardized postoperative } \\
\text { analgesia }\end{array}$ \\
\hline Abdominal drains & No routine abdominal drainage & $\begin{array}{l}\text { Abdominal drainage at } \\
\text { surgeon's discretion }\end{array}$ \\
\hline Nasogastric tube & $\begin{array}{l}\text { Total resection: Feeding NGT removed on POD } 5 \\
\text { Partial resection: No NGT }\end{array}$ & $\begin{array}{l}\text { Systematic NGT, removed at } \\
\text { surgeon's discretion }\end{array}$ \\
\hline Urinary catheter & Removed on POD 2 & $\begin{array}{l}\text { Removed at surgeon's } \\
\text { discretion }\end{array}$ \\
\hline $\begin{array}{l}\text { Postoperative } \\
\text { nutrition }\end{array}$ & $\begin{array}{l}\text { Fluid } 4 \mathrm{~h} \text { after surgery (max } 1 \mathrm{~L} / 24 \mathrm{~h} \text { ), enteral nutrition } 250 \mathrm{ml} / 24 \mathrm{~h} \text { through } \mathrm{NGT} \text { from } \\
\text { day of surgery, free fluids (whithout gaz) and } 2 \text { nutritional supplements per day from } \\
\text { POD } 1 \\
\text { Subtotal resection: light meal on POD 2, normal meal on POD } 3 \\
\text { Total resection: mixed light meal and enteral nutrition } 500 \mathrm{ml} / 24 \mathrm{~h} \text { on POD 3, light } \\
\text { meal on POD } 4\end{array}$ & $\begin{array}{l}\text { No standardized } \\
\text { reintroduction of fluids and } \\
\text { food }\end{array}$ \\
\hline Glycemic control & Insulin protocol in the event of hyperglycemia & Not routinely used \\
\hline Laxatives & Not routinely used & Not routinely used \\
\hline mobilization & Out of bed for at least $2 \mathrm{~h}$ on day of surgery; at least $8 \mathrm{~h}$ from day 1 & No protocol \\
\hline Systematic audit & Audit meeting every 2 months & None \\
\hline
\end{tabular}

LMW low molecular weight; IPC intermittent pneumatic compression; $P O N V$ postoperative nausea and vomiting; $N G T$ nasogastric tube; $P O D$ postoperative day

subtraction of the control group costs per patient to the ERP costs per patient and the ERP-specific costs per patient. The ERP-specific costs included the patient's logbook (€5), the preoperative carbohydrate drinks and finally the nutritional supplements $(€ 14)$. These costs (total of $€ 19$ ) were low and thus considered as negligible. Costs were obtained in Swiss francs (CHF) and then converted to euros $(€)$. The exchange rate used was $1 \mathrm{CHF}=0,93 €$, which was the official rate on June 10, 2020.

\section{Statistical analysis}

Continuous variables were compared using Mann-Whitney $\mathrm{U}$ test, whereas discrete variables were analyzed by means of Fisher's exact T test or Pearson Chi-square test. The arithmetic mean was considered as the most informative measure from a pharmaco-economic point of view. A $p$ value $<0.05$ was considered statistically significant. All analyses were performed using STATA ${ }^{\circledR}$ software (ver 16).

Results

Patient characteristics

During the study time, 157 gastric procedures were performed. Eleven wedge resections were excluded according 
to our inclusion/exclusion criteria. Hence, 144 patients met the inclusion criteria (see CONSORT flowchart, Fig. 1). Two patients had to be excluded in the control group, due to the lack of cost-related data. In the final analysis, ERP group included 81 patients and control group 63 patients. Both groups were similar in terms of demographics, comorbidities and surgical characteristics except for the surgical approach (laparoscopy was more frequently performed in the ERP group $(P<0.001)$. (Table 2).

Five patients presented a CCI $>50$ in the control group and 10 in the ERP group. These 15 patients represented $10 \%$ of the total sample size and were excluded from the costs analysis as stated in the method section.

\section{Costs analysis}

Costs details are shown in Table 3 . The mean total costs were $€ 39804$ for the control group and $€ 33418$ for the ERP group $(P=0.027)$. The mean intraoperative costs per patient were $€ 11613$ for the control group and $€ 11141$ for the ERP group $(P=0.839)$. The mean pre- and postoperative costs were $€ 28135$ and $€ 22276$ for control group and ERP group, respectively $(P=0.014)$. ERP was associated with lower costs for almost all items except for the disposable materials and the nutritionists. The difference of the mean total costs per patient between the two groups was $€ 6386(-36 \%)$ in favor of the ERP group.

\section{Perioperative outcomes}

Perioperative data are summarized in Table 4. Duration of operation as well as duration of anesthesia was significantly shorter in the ERP group $(P<0.001$ and $P=0.001$, respectively). Moreover, there was less blood loss in the ERP group $(P<0.001)$ and the length of stay was shorter in the ERP group $(P=0.026)$. On the other hand, the two groups were similar in terms of overall complication rate $(P=0.176)$, minor complication rate $(27 \%$ vs $26 \%$, $P=0.977)$, major complication rate $(35 \%$ vs $23 \%$, $P=0.130)$, median CCI $(22.1$ vs $19.6, P=0.320)$ and reoperation rate $(16 \%$ vs $10 \%, p=0.977)$. The overall rate of compliance to the ERAS protocol was $88 \%$.

\section{Subgroup analysis}

A subgroup analysis was performed by weighing the costs according to the CCI. Results are shown in Table 5.

\section{Discussion}

The present study shows that the implementation of an ERP protocol for gastric surgery allows a significant reduction of costs of $€ 6386$ per patient, in patients with moderate number of complications $(\mathrm{CCI} \leq 50)$. Moreover, higher costs reduction was observed as the complication

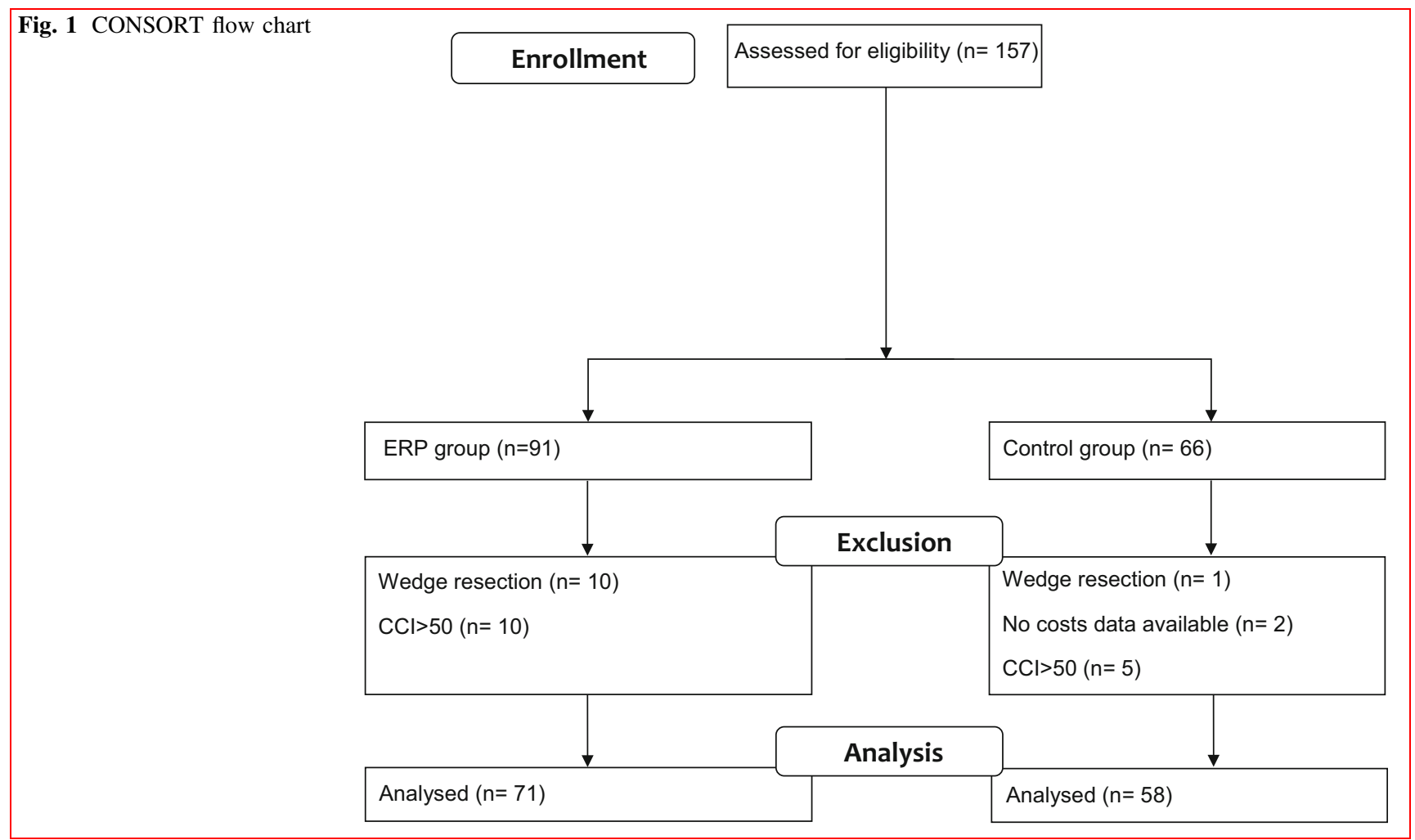


Table 2 Patient demographics and surgical details

\begin{tabular}{|c|c|c|c|}
\hline & ERP group $(n=71)$ & Control group $(n=58)$ & $P$ value \\
\hline Age (years)* & $60.6(14)$ & $61.5(14)$ & 0.784 \\
\hline Sex ratio $(M: F)$ & $42: 29$ & $37: 21$ & 0.591 \\
\hline \multicolumn{4}{|l|}{ ASA grade } \\
\hline I-II & 50 & 58 & \\
\hline III-IV & 21 & 0 & \\
\hline Charlson Index & $0.6(1)$ & $0.6(1)$ & 0.895 \\
\hline \multicolumn{4}{|l|}{ Surgical approach } \\
\hline Laparoscopic & 41 & 4 & $<0.001$ \\
\hline Open & 25 & 53 & $<0.001$ \\
\hline Converted & 5 & 1 & 0.154 \\
\hline \multicolumn{4}{|l|}{ Type of resection } \\
\hline Total gastrectomy & 42 & 36 & $0.591^{\$}$ \\
\hline Partial gastrectomy & 26 & 21 & $0.961^{\circ}$ \\
\hline Other & 3 & 1 & 0.415 \\
\hline \multicolumn{4}{|l|}{ Diagnosis } \\
\hline Malignant disease & 66 & 51 & 0.328 \\
\hline Benign disease & 5 & 7 & \\
\hline AJCC Stage & & & 0.758 \\
\hline I & 16 & 10 & \\
\hline II & 13 & 10 & \\
\hline III & 20 & 21 & \\
\hline IV & 9 & 6 & \\
\hline Preoperative chemotherapy & 40 & 25 & 0.135 \\
\hline
\end{tabular}

Values are *mean(s.d.). † Mann-Whitney test. § Pearson Chi-square test

Bold value indicates statistical significance $(p<0.05)$

AJCC American Joint Committee on Cancer

rates decrease, as shown in Table 5. Those results corroborate those of the study of Staiger et al. [25]. Their prediction model showed that each 10-point increase in CCI corresponded to a $14 \%$ increase to the baseline cost.

Our observations confirm the recent meta-analysis by Chen et al. [29] that included seven randomized controlled trials (RCTs), where hospitalization costs were found to be reduced in ERP group. In the present study, analyses of costs were more detailed and displayed significant savings in various type of care. Total mean costs were separated in two main categories: total intraoperative costs and total preoperative + postoperative costs. This second category of costs was significantly lower in the ERP group and included the majority of savings. The first one was the ICU/ IC costs. The majority of patients included in the ERP group did not stay in the ICU and spent just a few days in the IC compared to the control group, which is an interesting outcome of ERP per se. One of the reasons is probably the introduction of standardized anesthesia protocol and standardized care maps, guiding the postoperative period, thus decreasing monitoring needs and increasing patient's autonomy. The second main gain was in medication and laboratory tests. This is also explained by the care-maps use, leading to the elimination of unnecessary laboratory tests and a standardized postoperative medication plan. A nonsignificant reduction in costs for medical and nursing care was observed in the ERP group. This could be attributed to similar complication rate, since that factor strongly drive expenditures. Conversely, the costs for disposable materials were significantly higher in the ERP group. This is most likely linked with the more frequent use of laparoscopy. Moreover, with the introduction of ERP protocols, increased attention was paid to nutritional status with increased nutritional monitoring and thus increased costs of nutritionists.

The shorter LOS in the ERP group ( -3 days, $P=0.026)$ is consistent with data present in the literature $[19,20]$. ERAS ${ }^{\circledR}$ pathway has shown to reduce LOS [30] in colorectal [10, 13], pancreatic [22] and liver surgery [23]. In addition, several studies showed similar results for gastric 
Table 3 Detailed costs for the ERP and the standard group in euros

\begin{tabular}{|c|c|c|c|c|}
\hline & \multicolumn{4}{|c|}{ Mean cost per patient $(€)$} \\
\hline & ERP group* $(n=71)$ & Control group* $(n=58)$ & Difference (ERP-Control group) & $P$ value $\dagger$ \\
\hline Total intraoperative costs & $11,141(3195)$ & $11,613(28,191)$ & -472 & 0.839 \\
\hline Disposable materials & $4029(1769)$ & 2917 (1901) & 1111 & $<0.001$ \\
\hline Anesthesia and operating room & $7113(1992)$ & $8696(3787)$ & -1584 & 0.001 \\
\hline Total preoperative + postoperative costs & $22,276(16,572)$ & $28,135(24,527)$ & -5859 & 0.014 \\
\hline ICU/IC & $3078(4832)$ & $6151(8615)$ & -3073 & $<0.001$ \\
\hline Medical care & 4931 (2757) & $5207(3232)$ & -276 & 0.489 \\
\hline Nursing care & $7049(6786)$ & $7093(6043)$ & -44 & 0.340 \\
\hline Medication & $357(834)$ & $723(695)$ & -365 & $<0.001$ \\
\hline Physiotherapy & $300(411)$ & $546(796)$ & -246 & $<0.001$ \\
\hline Radiology & $535(689)$ & $837(1250)$ & -302 & 0.024 \\
\hline Laboratory & $764(771)$ & $1531(1900)$ & -766 & $<0.001$ \\
\hline Pathology & $2305(997)$ & $2442(1155)$ & -137 & 0.751 \\
\hline Blood transfusion and testing & $127(292)$ & $882(2485)$ & -754 & $<0.001$ \\
\hline Housing & $2181(1800)$ & $2147(1852)$ & 33 & 0.501 \\
\hline Interventional radiology and endoscopy & $305(644)$ & $310(620)$ & -5 & 0.605 \\
\hline Perioperative disposable material & $265(767)$ & 339 (966) & -73 & 0.389 \\
\hline Nutritionists & $189(310)$ & $52(149)$ & 137 & $<0.001$ \\
\hline Total costs & $33,418(17,901)$ & $39,804(27,288)$ & -6386 & 0.027 \\
\hline
\end{tabular}

Values are *mean(s.d.). $†$ Mann-Whitney test. Bold value indicates statistical significance $(p<0.05)$

ICU Intensive care unit, IC intermediate care unit. CCI Comprehensive complication index

Table 4 Perioperative outcomes

\begin{tabular}{|c|c|c|c|}
\hline & ERP group* $(n=71)$ & Control group* $(n=58)$ & $P$ value \\
\hline Duration of operation (min) & $207(63)$ & $249(55)$ & $<0.001$ \\
\hline Duration of anesthesia (min) & $280(79)$ & $322(62)$ & $<0.001$ \\
\hline Blood loss (ml) & $173(224)$ & $392(347)$ & $<0.001^{\dagger}$ \\
\hline \multicolumn{4}{|l|}{ Complications } \\
\hline Minor (I-II) & 21 & 24 & $0.162^{\S}$ \\
\hline Major (III-IV) & 11 & 34 & $<0.001^{\mathrm{s}}$ \\
\hline Death (V) & 0 & 0 & $0.376^{\S}$ \\
\hline CCI & $12.9(15.6)$ & $17.9(17.2)$ & $0.088^{\dagger}$ \\
\hline Reoperation & 3 & 10 & $0.015^{\S}$ \\
\hline LOS & $14(13)$ & $17(11)$ & 0.026 \\
\hline Readmission & 10 & 4 & 0.173 \\
\hline
\end{tabular}

Values are *mean(s.d.). † Mann-Whitney test. § Pearson Chi-square test

Bold value indicates statistical significance $(p<0.05)$

CCI Comprehensive complication index, LOS Length of stay

surgery [16, 17, 29, 31]. A recent meta-analysis including six RCTs showed a shorter LOS of 2.65 days for the 'fasttrack' groups $(P<0.001)$ [16]. Of note, our LOS is globally longer than reported in the literature. Selection of patients is the major reason for that. In fact, when looking at the inclusion/exclusion criteria of these studies, we can observe that patients $>75$ years, with an American Society of Anesthesiologists (ASA) score of III or IV as well as total gastrectomy for advanced stage cancer, are most often excluded. In our study, we included all patients, and age, 
Table 5 Costs according to CCI

\begin{tabular}{|c|c|c|c|c|}
\hline & \multicolumn{4}{|c|}{ Mean cost per patient $(€)$} \\
\hline & ERP group* & Control group* & Difference (ERP - Control group) & $P$ value $\dagger$ \\
\hline CCI 20 & $25,940(12,176)$ & 29,253 (6199) & -3313 & 0.014 \\
\hline CCI 30 & $28,045(12,493)$ & $30,961(8070)$ & -2916 & 0.017 \\
\hline CCI 40 & $31,899(17,568)$ & $32,561(9341)$ & -662 & 0.048 \\
\hline CCI 50 & $33,418(17,901)$ & $39,804(27,288)$ & -6386 & 0.027 \\
\hline
\end{tabular}

Values are *mean(s.d.). $\dagger$ Mann-Whitney test

Bold value indicates statistical significance $(p<0.05)$

CCI Comprehensive complication index

pre-existing co-morbidities or advanced cancer stage were not considered as exclusion criteria.

On the other hand, we observed discordant results regarding complication rate. In the present study, the complication rate (both minor and major) was similar as in the meta-analysis of $\mathrm{Li}$ et al. [16]. However, ERAS $®$ pathway has commonly shown to reduce complication rate in colorectal [10, 13], pancreatic [22] and liver surgery [23]. Our nonsignificant results concerning morbidity could be explained by the fact that ERP was already implemented in our department many years ago in several different surgeries (colorectal, pancreatic, and liver). As suggested by a previous study in liver surgery [32], this may have influenced both surgeons and care givers for the control group.

Finally, our results confirm those of the meta-analysis of $\mathrm{Yu}$ et al. [31], which showed a 2-day LOS decrease $(P<0.001)$ and a decrease in costs of $\$ 506(P<0.001)$ in 'fast-track' patients, with a comparable complication rate and readmission rate.

As shown in the literature, implementation of ERP protocols needs an initial consequent investment, but is later associated with important cost reductions $[10,22,23,33]$. In our department, ERAS ${ }^{\circledR}$ was implemented in 2011 for colorectal surgery and gradually applied to other types of abdominal surgery. Costs of education and training of each team-member were therefore granted. Introducing new ERPs for other types of surgery in the same department will decrease more and more the implementation costs that may finally become negligible.

The present study has some limitations that need to be addressed. The most important limitation is the increased use over time of laparoscopy in gastric surgery, clear bias in favor of ERP patients, as showed in the literature [34]. Another limitation is the difficulty to differentiate between the pathophysiological effects of the ERP protocol and benefits of standardization itself. Moreover, the retrospective design with subsequent missing data could induce some bias. However, a prospective randomized trial seems today not ethical, as ERAS ${ }^{\circledR}$ pathway has become standard of care in our department, with proven benefits for patients and their outcome. Moreover, a randomization within a surgical department with ERAS protocols in other surgical specialties is not possible, as prior ERAS habits significantly influence outcome in the control group [32].

On the other hand, an important strength of the present study is its detailed real costs analysis. This real cost analysis may allow to better understand some specific aspects of perioperative care influenced by the implementation of an enhanced recovery program.

\section{Conclusion}

ERP is cost-effective in gastric surgery patients, with higher costs savings in patients with no or limited postoperative complications.

Acknowledgements The authors would like to thank Dr. Ismail Labgaa for reviewing and editing the text and Valérie Addor, the Clinical Nurse in charge of the ERAS Program.

Funding Open Access funding provided by Université de Lausanne. No funding source.

\section{Declarations}

Conflict of interest The authors have no conflicts of interest or funding to declare in relation to this work.

Ethical approval The study protocol was approved by the local Ethical Committee (CER-VD, protocol number: 2016-01075). The present work was presented in parts at the Swiss Annual Congress of Surgery 2019.

Informed consent All individual participants included in the study had signed the institutional general informed consent for clinical research. 
Open Access This article is licensed under a Creative Commons Attribution 4.0 International License, which permits use, sharing, adaptation, distribution and reproduction in any medium or format, as long as you give appropriate credit to the original author(s) and the source, provide a link to the Creative Commons licence, and indicate if changes were made. The images or other third party material in this article are included in the article's Creative Commons licence, unless indicated otherwise in a credit line to the material. If material is not included in the article's Creative Commons licence and your intended use is not permitted by statutory regulation or exceeds the permitted use, you will need to obtain permission directly from the copyright holder. To view a copy of this licence, visit http://creativecommons. org/licenses/by/4.0/.

\section{References}

1. Lassen K, Soop M, Nygren J et al (2009) Consensus review of optimal perioperative care in colorectal surgery: Enhanced Recovery After Surgery (ERAS) Group recommendations. Arch Surg 144:961-969

2. Lassen K, Coolsen MM, Slim K et al (2012) Guidelines for perioperative care for pancreaticoduodenectomy: Enhanced Recovery After Surgery (ERAS(R)) Society recommendations. Clin Nutr 31:817-830

3. Gustafsson UO, Scott MJ, Schwenk W et al (2012) Guidelines for perioperative care in elective colonic surgery: Enhanced Recovery After Surgery (ERAS(R)) Society recommendations. Clin Nutr 31:783-800

4. Nygren J, Thacker J, Carli F et al (2012) Guidelines for perioperative care in elective rectal/pelvic surgery: Enhanced Recovery After Surgery (ERAS(R)) Society recommendations. Clin Nutr $31: 801-816$

5. Gustafsson UO, Scott MJ, Schwenk W et al (2013) Guidelines for perioperative care in elective colonic surgery: Enhanced Recovery After Surgery (ERAS $((\mathrm{R})))$ Society recommendations. World J Surg 37:259-84. https://doi.org/10.1007/s00268-012-1772-0

6. Lassen K, Coolsen MM, Slim K et al (2013) Guidelines for perioperative care for pancreaticoduodenectomy: Enhanced Recovery After Surgery (ERAS(R)) Society recommendations. World J Surg 37:240-58. https://doi.org/10.1007/s00268-0121771-1

7. Nygren J, Thacker J, Carli F et al (2013) Guidelines for perioperative care in elective rectal/pelvic surgery: Enhanced Recovery After Surgery (ERAS((R))) Society recommendations. World J Surg 37:285-305. https://doi.org/10.1007/s00268-012-1787-6

8. Melloul E, Hubner M, Scott M et al (2016) Guidelines for Perioperative Care for Liver Surgery: Enhanced Recovery After Surgery (ERAS) Society Recommendations. World J Surg 40:2425-40. https://doi.org/10.1007/s00268-016-3700-1

9. Varadhan KK, Neal KR, Dejong CH et al (2010) The enhanced recovery after surgery (ERAS) pathway for patients undergoing major elective open colorectal surgery: a meta-analysis of randomized controlled trials. Clin Nutr 29:434-440

10. Roulin D, Blanc C, Muradbegovic M et al (2014) Enhanced recovery pathway for urgent colectomy. World J Surg 38:2153-9. https://doi.org/10.1007/s00268-014-2518-y

11. Lemanu DP, Singh PP, Stowers MD et al (2014) A systematic review to assess cost effectiveness of enhanced recovery after surgery programmes in colorectal surgery. Colorectal Dis 16:338-346

12. Hughes MJ, McNally S, Wigmore SJ (2014) Enhanced recovery following liver surgery: a systematic review and meta-analysis. HPB (Oxford) 16:699-706
13. Greco M, Capretti G, Beretta L et al (2014) Enhanced recovery program in colorectal surgery: a meta-analysis of randomized controlled trials. World J Surg 38:1531-41. https://doi.org/10. 1007/s00268-013-2416-8

14. Findlay JM, Gillies RS, Millo J et al (2014) Enhanced recovery for esophagectomy: a systematic review and evidence-based guidelines. Ann Surg 259:413-431

15. Mortensen K, Nilsson M, Slim K et al (2014) Consensus guidelines for enhanced recovery after gastrectomy: Enhanced Recovery After Surgery (ERAS(R)) Society recommendations. Br J Surg 101:1209-1229

16. Li MZ, Wu WH, Li L et al (2018) Is ERAS effective and safe in laparoscopic gastrectomy for gastric carcinoma? A meta-analysis. World J Surg Oncol 16:17

17. Ding J, Sun B, Song P et al (2017) The application of enhanced recovery after surgery (ERAS)/fast-track surgery in gastrectomy for gastric cancer: a systematic review and meta-analysis. Oncotarget 8:75699-75711

18. Sahoo MR, Gowda MS, Kumar AT (2014) Early rehabilitation after surgery program versus conventional care during perioperative period in patients undergoing laparoscopic assisted total gastrectomy. J Minim Access Surg 10:132-138

19. Liu XX, Pan HF, Jiang ZW et al (2016) "Fast-track" and "minimally invasive" surgery for gastric cancer. Chin Med J (Engl) 129:2294-2300

20. Liu G, Jian F, Wang X et al (2016) Fast-track surgery protocol in elderly patients undergoing laparoscopic radical gastrectomy for gastric cancer: a randomized controlled trial. Onco Targets Ther 9:3345-3351

21. Roulin D, Donadini A, Gander S et al (2013) Cost-effectiveness of the implementation of an enhanced recovery protocol for colorectal surgery. Br J Surg 100:1108-1114

22. Joliat GR, Labgaa I, Petermann D et al (2015) Cost-benefit analysis of an enhanced recovery protocol for pancreaticoduodenectomy. Br J Surg 102:1676-1683

23. Joliat GR, Labgaa I, Hubner M et al (2016) Cost-benefit analysis of the implementation of an enhanced recovery program in liver surgery. World J Surg 40:2441-2450. https://doi.org/10.1007/ s00268-016-3582-2

24. Kim JW, Kim WS, Cheong JH et al (2012) Safety and efficacy of fast-track surgery in laparoscopic distal gastrectomy for gastric cancer: a randomized clinical trial. World J Surg 36:2879-2887. https://doi.org/10.1007/s00268-012-1741-7

25. Staiger RD, Cimino M, Javed A et al (2018) The Comprehensive Complication Index $\left(\mathrm{CCI}^{\circledR}\right)$ is a novel cost assessment tool for surgical procedures. Ann Surg 268:784-791

26. Slankamenac K, Graf R, Barkun J et al (2013) The comprehensive complication index: a novel continuous scale to measure surgical morbidity. Ann Surg 258:1-7

27. Dindo D, Demartines N, Clavien PA (2004) Classification of surgical complications: a new proposal with evaluation in a cohort of 6336 patients and results of a survey. Ann Surg 240:205-213

28. Chagnon M, Audette LM, Lebrum L et al (1978) A patient classification system by level of nursing care requirements. Nurs Res 27:107-112

29. Chen S, Zou Z, Chen F et al (2015) A meta-analysis of fast track surgery for patients with gastric cancer undergoing gastrectomy. Ann R Coll Surg Engl 97:3-10

30. Muller MK, Dedes KJ, Dindo D et al (2009) Impact of clinical pathways in surgery. Langenbecks Arch Surg 394:31-39

31. Yu Z, Zhuang CL, Ye XZ et al (2014) Fast-track surgery in gastrectomy for gastric cancer: a systematic review and metaanalysis. Langenbecks Arch Surg 99:85-92

32. Labgaa I, Jarrar G, Joliat GR et al (2016) Implementation of Enhanced Recovery (ERAS) in Colorectal Surgery Has a Positive 
Impact on Non-ERAS Liver Surgery Patients. World J Surg 40:1082-1091. https://doi.org/10.1007/s00268-015-3363-3

33. Lee L, Li C, Robert N et al (2013) Economic impact of an enhanced recovery pathway for oesophagectomy. Br J Surg 100:1326-1334

34. Huscher CG, Mingoli A, Sgarzini G et al (2005) Laparoscopic versus open subtotal gastrectomy for distal gastric cancer: five- year results of a randomized prospective trial. Ann Surg 241:232-237

Publisher's Note Springer Nature remains neutral with regard to jurisdictional claims in published maps and institutional affiliations. 